Article

\title{
Examining Supportive Evidence for Psychosocial Theories of Aging within the Oral History Narratives of Centenarians
}

\author{
Melinda Heinz ${ }^{1, *}$, Nicholas Cone ${ }^{2}$, Grace da Rosa ${ }^{3}$, Alex J. Bishop ${ }^{4}$ and Tanya Finchum ${ }^{5}$ \\ 1 Psychology Department, Upper Iowa University, Fayette, IA 52142, USA \\ 2 Psychology Department, Loras College, Dubuque, IA 52001, USA; Nicholas.cone@loras.edu \\ 3 Gerontology Department, Georgia State University, Atlanta, GA 30303, USA; gdarosa@gsu.edu \\ 4 Human Development and Family Science Department, Oklahoma State University, \\ Stillwater, OK 74074, USA; alex.bishop@okstate.edu \\ 5 Oklahoma Oral History Research Program, Oklahoma State University, Stillwater, OK 74078, USA; \\ tanya.finchum@okstate.edu \\ * Correspondence: heinzm@uiu.edu; Tel.: +1-563-425-5912 \\ Academic Editor: Stephen Katz \\ Received: 28 February 2017; Accepted: 14 April 2017; Published: 19 April 2017
}

\begin{abstract}
Oral history provides researchers opportunities to assess narratives and compare them to existing theories of aging. Oftentimes the discussion of psychosocial theories of aging does not include the oldest-old. The purpose of this study was to assess evidence of psychosocial theories of aging within oral history narratives from a subsample of 20 centenarians from the Oklahoma 100 Year Life Oral History Project. Analysis utilized seven theories: Activity Theory, Continuity Theory, Disengagement Theory, Theory of Gerotranscendence, Modernization Theory, Selective Optimization with Compensation (SOC) Theory, and Socioemotional Selectivity Theory (SST). Researchers used content analysis to assess each oral history narrative and noted Activity Theory and Gerotranscendence had the most evidence. Most centenarians described how they were extremely active well into older adulthood. Common themes across oral history narratives indicated that centenarians maintained a preference for activity such as formal work. Centenarians also reported a readiness for death and little fear of it. In addition, increased time spent reflecting on spirituality and religion indicated changes in self-discovery. Identification of Disengagement and Socioemotional Selectivity were sparse in the transcripts. It is possible that to reach such longevity, centenarians relied on their communities and support networks to achieve this status. It is also possible that centenarians outlived individuals in their social networks who were emotionally fulfilling. Further qualitative work should assess evidence of psychosocial theories among other long-lived older adults.
\end{abstract}

Keywords: oral history; psychosocial theories; centenarians; aging; narrative

\section{Introduction}

\subsection{Evidence of Psychosocial Theories among the Oldest-Old}

Many of the mysteries of living 100 or more years have remained unsolved. Many biogerontologists have argued that human life-expectancy is largely due to genetics [1,2]. However, it has been well-documented that only $20 \%-30 \%$ of human life-expectancy is explained by genetic variation [2-4]. Some researchers have concluded that psychosocial resources play an essential role in explaining aging processes beyond biology; Poon et al., and Silverstein et al. [5,6] noted that psychosocial theories of aging serve as useful tools to examine unexplained complexities in human aging. Such theories maintain a capacity to be "reconceptualized" despite decreasing rates 
of mortality. Gondo [7] argued that even some non-logical theories, such as Gerotranscendence, might fit best in scientific inquiries addressing secrets of longevity. This paper attempts to highlight some of these notions related to the centenarian longevity. The purpose of this study was to assess evidence of psychosocial theories of aging within oral history narratives from a subsample of 20 centenarians from the Oklahoma 100 Year Life Oral History Project The overall guiding research question was to find evidence for which psychosocial theories centenarians were more likely to endorse. We hypothesize that there will be more evidence for Activity, Continuity, Gerotranscendence, and Selective Optimization with Compensation. Given that these centenarians are survivors, we anticipate that evidence of Activity and "engagement" (rather than Disengagement) is more likely to characterize their lives. Likewise, we imagine that many of the activities and interests that were important to centenarians earlier in life may still be important to them in older adulthood (Continuity). We anticipate evidence of gerotranscendence as older adults reflect on their lives and turn inward in order to prepare for future death. Lastly, in order to reach 100 years of age, we anticipate that centenarians had to engage in significant compensation in order to successfully adapt and cope with numerous life events, historical changes, and perhaps their own health changes (Selective Optimization with Compensation). This study will add to previous research on the unique group of selective survivors who (in many cases) overcame adversity, diseases, and difficult life events. Despite these challenges, these centenarians are aging well and may provide clues for their healthy longevity.

\subsection{Centenarians}

The oldest-old are becoming an ever-present demographic in the aging population. Some biodemographers have claimed that half or more children born since the year 2000 will survive to their 100th birthday [8]. By 2050, it is projected that close to a million or more persons will be centenarians in the United States [9]. Consequently, aging experts have begun to ask: Will most humans become centenarians [10]? However, insights from the lives of centenarians remain largely absent in theoretical literature [7]. Centenarians remain an understudied population uniquely different from younger age cohorts. In fact, the average centenarian is more likely to have outlived family and social network ties, witnessed decades of socio-cultural and geopolitical changes, endured multiple and often simultaneous health or functional disablements, and transitioned across varying levels of long-term care [7]. Therefore, it is imperative to assess the extent to which life-expectancy may encompass psychosocial explanations beyond basic genetic understanding [5]. Qualitative research is one useful alternative approach for exploring established theoretical models as well as deriving new modes of thought. For example, Reichstadt et al., and Baum [11,12] both qualitatively assessed centenarian well-being or successful aging. Assessing psychosocial theories qualitatively may also be advantageous to learn more about what Poon [5] identified as a lack of aging research focused on psychosocial factors. This research seeks to assist with addressing this acknowledged gap in centenarian research.

\subsection{Oral History}

Baum [13] and Collins and Bloom [14] define oral history research as a research method for assessing the stories and records that aid in the understanding of previous events in history as well as the feelings surrounding such events. Although oral history research utilizes less structured approaches than other methodologies (e.g., researchers are encouraged to follow cultural norms, practices, and intuition when conducting an interview rather than relying on standardized interview techniques), asking similar questions across participant interviews generates consistency [15]. The flexible style of oral history research offers advantages to participants, including greater openness story sharing and provides participants with greater control in setting the pace of the interview. Lastly, Thomson [15] suggests that there is no "right way" to conduct an oral history interview. 
Relatedly, much of gerontology research is focused on deficits and challenges of aging. However, oral history research allows an opportunity to understand positive aspects of aging (e.g., assessing growth, wisdom, and meaning of experiences and life events) [16].

In a practical sense, Butler [16] states oral history research encourages us to understand how various factors shape and affect an individual's life. To that end, such information allows us to understand the longevity of centenarians in a unique way. Butler [16] argues that the desire for self-awareness may be more important in older adulthood than at any other point in life. This is particularly true of the oldest-old, including centenarians, who often seek congruence or balance between one's past life achievements and present conditions of self-being $[17,18]$.

Oral history research may be beneficial to the participant and may influence other relationships. For example, Butler [16] reported that it is possible for family members to learn new things about a loved one by listening to an oral history interview and consequently create a greater sense of intimacy.

\section{Psychosocial Theories}

Some of the most common psychosocial theories discussed in the literature are Activity, Continuity, Disengagement, Gerotranscendence, Modernization, Selective Optimization with Compensation and Socioemotional Selectivity. The Theory of Gerotranscendence is a well-known psychosocial theory of positive aging and has been applied to centenarians $[18,19]$. However, less is known about how the other selected theories relate to centenarians. Each psychosocial theory underwent a broader category classification of either Classical, Modern, or New period theories in gerontology (Table 1). The broader categories were created by Schroots [20] and are based on the time-period in which they were developed. Classical theories typically refer to theories developed during the 1940s to 1970s. Modern theories typically refer to theories developed during the 1970s to 1990s, and the New Period theories typically refer to theoretical developments during the 1980s and 1990s [20].

Table 1. Categorization of psychosocial theories of aging.

\begin{tabular}{cc}
\hline Classical Theories \\
\hline 1. & Disengagement Theory \\
2. & Activity Theory \\
\hline Modern Theories \\
\hline 1. & Modernization Theory \\
2. & Continuity Theory \\
3. & Socioemotional Selectivity Theory \\
\hline New Period Theories \\
\hline 1. & Selective Optimization with Compensation \\
\hline
\end{tabular}

The Activity Theory was first introduced by Cavan et al. [21] and Havinghurst and Albrecht [22]. General principles guiding the theory assert that older adults naturally gravitate toward and participate in community, society, and social roles [23]. An increased activity level is associated with greater life satisfaction and consequently greater well-being in older adulthood [24]. However, critiques of the theory include concern that there are other factors that may explain the relationship between life satisfaction and increased activity level (e.g., socioeconomic status, personality, lifestyle, etc. [24]). The Activity Theory has been used extensively in research and is often used when assessing or predicting successful aging. Researchers have noted significant evidence of Activity Theory as it relates to well-being and survival in older adults [25].

The Continuity Theory, first developed by Atchley [26]. Diggs [24] asserts that even as older adults age they continue to be interested in and participate in previous hobbies, goals, roles, and activities. Continuity can be looked at from both internal and external viewpoints. Internally, older adults may be persuaded to continue to engage in previous activities due to the sense of stability and security they 
provide [26]. External continuity may have more to do with fulfilling expectations related to previous roles or behaviors [24]. Critics of this theory maintain that Continuity Theory may be more applicable and useful for healthy older adults. For example, Diggs [24] noted the difficulties of maintaining continuity when faced with medical conditions, disabilities, or memory impairment. Continuity Theory has often been paired with Activity Theory in gerontological research. Similar to Activity Theory, Continuity has also been included in literature on successful aging [27] as well as lifelong learning [28].

Disengagement Theory was developed by Cummings and Henry [29]. From this theoretical perspective, older adults willingly give up roles and disengage from society as they age [24]. Disengagement Theory has been used to explore role changes in late life [30] such as widowhood [31]. However, it is not prevalent in recent gerontological research, and theorists argue that it is not in fact a component of successful aging [32]. Critics of the theory argue that disengagement is not universal among all older adults [33] and that when the theory is tested with older adults, there is little evidence to support disengagement [32].

Lars Tornstam first developed the Theory of Gerotranscendence in 1989. The theory includes three specific levels including the (1) cosmic; (2) the self; and (3) social and individual relations [34]. The cosmic level is related to perceived changes to time, space, and decreased fear of death. Individuals take on new characterizations of the self, including increased understanding of hidden aspects of the self. There is also a significant shift away from the self and on to others (i.e., altruism). Social and individual relations may refer to increased focus on solitude and pondering as well as some role relinquishment [34]. The theory has been used to better understand the importance of reminiscence in older adulthood [35], spirituality [36] and life satisfaction [37]. Some researchers have been critical of the view that spirituality may change with age. Instead, Dalby [36] pointed out that dimensions of spirituality may change due to other reasons. Likewise, questions surrounding the universality of the theory have been raised. For example, Jewell [38] theorized that gerotranscendence may be dependent on the individual or culture.

Modernization Theory was developed by Cowgill and Holmes [39] and states that as society becomes more modern, the status of older adults declines [40]. For example, the usefulness of older adults eroded with the shift from an agricultural to a more industrial society [39]. The theory has been used to understand negative attitudes toward aging [41], as well as family relationships [42] and family caregiving dynamics [43]. Achenbaum and Sterns [44] note there needs to be more agreement regarding when modernization first began as well as classifying stages within modernization. The authors go on to discuss the complexities of how modernization has affected various age groups in different ways. Consequently, the main criticisms of the theory are that it is broad and needs to be more appropriately specified [43].

Baltes and Baltes [45] developed the Selective Optimization with Compensation Theory and proposed older adults can successfully adapt and cope with growing older by focusing on the gains and strengths (rather than losses) and engage in compensation strategies when encountering challenges. This theory has been used as a framework to help understand successful aging in older adults in a number of different ways, including adapting to disability [46] and memory decline [47]. A criticism of the theory is that it is a bit reactive rather than proactive. Ouwehand et al. [48] argue that theories or models that focus on proactive coping may lead to greater understanding of successful aging.

Socioemotional Selectivity Theory was proposed by Carstensen et al. [49] and states that when individuals are faced with limited time, they prioritize emotionally meaningful experiences and relationships rather than focusing on more future-oriented goals [50]. Carstensen et al. [49] goes on to explain that changes in priorities are also likely to influence social networks (i.e., paring down a social network to include only the closest of relationships is thought to facilitate the emotion regulation [50] that may be present when faced with impending mortality). Socioemotional Selectivity Theory has been used to explore the social networks and relationships of older adults [51,52], as well as motivation [53] and emotion [54]. One criticism of the theory is that, although many of the findings have been validated in research (i.e., older adults narrowing their social networks), many of the studies only assess this 
from a cross-sectional perspective. It is possible that there are cohort differences in preferences for social networks and goal-setting behaviors [24].

Although there are many theories of aging discussed in the literature, gerontologists do a poor job of discussing how these theories may apply to the oldest-old. As gerontologists, considering the oldest-old in our discussions of aging will (only) help to solidify and further theories on aging. As Silverstein et al. [6] pointed out, when theories are missing from research, it lacks depth. Theories provide context and richness to research in gerontology. Theory also drives research questions, methods, and hypothesis testing. It is also our hope that this research will foster new ways of thinking about how psychosocial theories of aging apply to the oldest-old.

\section{Method}

A total of $n=112$ centenarians living in Oklahoma were identified and recruited to participate in the Oklahoma 100 Year Life Oral History Project. The names of centenarians were obtained or nominated from aging-service network partners (e.g., Oklahoma Centenarians, Centenarians of Tulsa, Oklahoma Aging Services Division, and Oklahoma State University Family Consumer Science Extension) and the Oklahoma Cooperative Extension Network.

Oklahoma is geographically situated in the Southern Plains of the United States. With a population just over four million people, Oklahoma maintains an economy largely based in agricultural farming and ranching, as well as oil/petroleum and natural gas exploration and production. Oklahoma has a relatively diverse population, most notably the second-largest American Indian population in the United States [55]. Notable socio-historical events specific to the state of Oklahoma include the 1921 Tulsa Race Riot, the Oil Boom of the 1920s, and the 1930s Dust Bowl. More recent historical events include the 1995 Oklahoma City Bombing of the Alfred P. Murrah Federal Building and the 1999 and 2013 Moore Tornadoes.

All participants were required to sign an Institutional Review Board (IRB) consent form and signed a release form stating that they were comfortable with the oral history interview and archival of the transcription at the Oklahoma State University library website. In addition, participants were screened for cognitive orientation using the Mini-Mental Status Short-Form (MMSE-B) [56]. Cognitive screening of centenarian research participants in social-behavioral investigations is a recommended and acceptable methodological practice [57]. Although there are no recommended cut-off scores for use of MMSE-BV with persons 100+ years of age, a cut-off score ranging from 12 to 14 has been reported as appropriate for clinical use with normative to mild cognitively impaired older adults [58]. However, advanced old age, lower educational attainment, and sensory impairment (e.g., vision/hearing) tend to reduce overall MMSE scores and require a scoring adjustment for the allowance of additional errors [57,59]. We used a corrected cut-off score of 10 or more correct responses as indicative of cognitive orientation. For purposes of this study, we defined cognitively intact participants as oriented and not demented.

\subsection{Participants}

This study analyzed a subset of 20 centenarians from the Oklahoma 100 Year Life Oral History Project that had been fully transcribed, audited, and reviewed and approved. This particular investigation was conducted to determine general themes within the oral history narratives that might provide preliminary support or disconfirmation of common psychosocial theories. Nine participants were male and eleven were female. Participants were all 100 years of age or older. When choosing the subsample of centenarians, utilization of maximum variation sampling allowed for a diverse selection of participants [60]. Parameters for selection included diversity in race, education level, and marital status. A summary of centenarian demographic characteristics can be found in Table 2 . Reference [60] (p. 229) states that such diversity in participants "allow[s] for a greater range of application of the findings by consumers of the research." The inclusion of a diverse cultural group was of importance when assessing evidence of psychosocial theories within oral history narratives. 
Dilsworth-Anderson and Cohen [61] pointed out that conducting research with diverse cultures adds to increased understanding and meaning.

Some centenarians were still working and some were retired. Some centenarians were also classified as ethnic minorities. Centenarians also had a wide range of careers including educators, engineers, a broadcaster, farmers, stay-at-home parents, etc. In addition, some centenarians grew up very poor, whereas other centenarians came from wealthier families. The family dynamics of centenarians were also diverse. For example, some experienced the death of a parent during childhood, some were predominately raised by another family member, and some in more traditional "nuclear" families.

As a way to standardize sampling procedures, the age of all participants was validated (Table 3). In particular, we adopted suggested age validation procedures recommended by [62] (pp. 9-10). This procedure involves a three-level hierarchical inquiry of validation documents including: (a) Evidence in the form of a primary or legal evidence of age such as a birth certificate or death records, marriage records or other legally binding document; (b) In the event a birth record cannot be produced, a request for secondary proof of age in the form of government-issued identity cards, passports, a state-issued driver's license, voter/tax registration, military registers, or family/household bibles or genealogy books is made; (c) In the event that the person cannot produce legal or secondary evidence, then a final peripheral account or recorded evidence associated with specific life events such as birth/birthday announcement in a newspaper, marital/anniversary or divorce announcement, migration or residential change record, birth announcements of children, family burial information, and census or data forms is requested to help back-date the person's current age.

Table 2. Summary of frequencies, means, and standard deviations of demographic variables.

\begin{tabular}{|c|c|c|c|c|}
\hline Variable & Frequency & Percentage & Mean & Standard Deviation \\
\hline \multicolumn{5}{|l|}{ Gender } \\
\hline Male & 9 & 45.0 & & \\
\hline Female & 11 & 55.0 & & \\
\hline Age & & & 100.60 & 1.231 \\
\hline \multicolumn{5}{|l|}{ Race } \\
\hline White-Caucasian & 14 & 70.0 & & \\
\hline Black or African American & 2 & 10.0 & & \\
\hline Multi-Race & 4 & 20.0 & & \\
\hline \multicolumn{5}{|l|}{ Education } \\
\hline Grade School & 2 & 10.0 & & \\
\hline Some High School & 3 & 15.0 & & \\
\hline High School Diploma & 4 & 20.0 & & \\
\hline Trade School or Vocational Degree & 1 & 5.0 & & \\
\hline Some College & 3 & 15.0 & & \\
\hline Associate Arts Degree & 1 & 5.0 & & \\
\hline College Degree & 2 & 10.0 & & \\
\hline Graduate Degree & 3 & 15.0 & & \\
\hline Ph.D./Doctoral Degree & 1 & 5.0 & & \\
\hline \multicolumn{5}{|l|}{ Marital Status } \\
\hline Never Married & 1 & 5.0 & & \\
\hline Married & 3 & 15.0 & & \\
\hline Divorced & 1 & 5.0 & & \\
\hline Widowed & 15 & 75.0 & & \\
\hline
\end{tabular}

Table 3. Age validation.

\begin{tabular}{ccc}
\hline \multicolumn{1}{c}{ Age Validation } & $\boldsymbol{n}$ & Percentage \\
\hline Tier I-Primary Legal & & \\
\hline Birth Certificate & 6 & 30.0 \\
Marriage License & 1 & 5.0 \\
\hline Tier II-Secondary Legal & & \\
\hline Driver's License/State ID & 7 & 35.0 \\
\hline Tier III-Documents & & \\
\hline Newspaper/Other & 6 & 30.0 \\
\hline
\end{tabular}




\subsection{Procedure}

During the oral history interview, participants were asked questions about their lives, including special traditions and memories they had growing up, influential life events, secrets to longevity, sense of legacy, and whether or not they felt they had thought about the meaning of living or being 100 or more years. Though structured, the conversation was also free flowing in nature as [15] talked about the importance of taking into consideration gender, culture, and other individual differences. In most cases, two researchers undertook the oral history narrative with the centenarian. Interviews were done in a single session. A single-session interview was the most efficient given the time and resources needed to interview centenarians who tended to be geographically dispersed across the entire state of Oklahoma. Researchers strived to complete the interviews in 30-45 min to reduce the likelihood of fatigue. However, during instances when interviews took longer, participants were asked if they were interested in continuing the interview. Interviews ranged from 37.30 to $103.91 \mathrm{~min}(\mathrm{M}=68.94 \mathrm{~min} ; \mathrm{SD}=19.87 \mathrm{~min})$. Transcription occurred after each oral history interview and researchers used a content analysis approach to understanding the data. As indicated in [63], researchers engaged in content analysis by reviewing data in its entirety. Next, pieces were chosen to fit under higher order headings (in this case, each respective psychosocial theory).

The theories used for analysis were Activity, Continuity, Disengagement, Gerotranscendence, Modernization, Selective Optimization with Compensation and Socioemotional Selectivity. Table 4 provides a brief definition and description of each theory. Two researchers independently analyzed narratives and then discussed the theoretical findings together. Discrepancies were addressed through discussion and were resolved. A third researcher also verified the findings after all narrative analyses were completed.

Table 4. Definitions of psychosocial theories.

\begin{tabular}{|c|c|}
\hline Theory & Definition \\
\hline Activity Theory & Social participation and engagement aids in life satisfaction [22]. \\
\hline \multirow[t]{2}{*}{ Continuity Theory } & $\begin{array}{l}\text { "... new directions are closely linked to and elaborate upon already existing identity." } \\
\text { [25] p. } 187 .\end{array}$ \\
\hline & $\begin{array}{l}\text { Continuity can apply internally (e.g., the self and identity) or externally (routines, } \\
\text { activities, etc.) [25]. }\end{array}$ \\
\hline Disengagement Theory & The older adult experiences a natural and mutual separation from society [63] \\
\hline \multirow[t]{2}{*}{ Gerotranscendence Theory } & $\begin{array}{l}\text { A change in priorities from materialistic and rational to cosmic and spiritual } \\
\text { perspectives [33]. }\end{array}$ \\
\hline & $\begin{array}{l}\text { Decreased fear of death, redefining perceptions of life and death, and increased time } \\
\text { spent meditating and pondering about life [33]. }\end{array}$ \\
\hline Modernization Theory & Older adult status declines as society becomes more modernized [39]. \\
\hline $\begin{array}{l}\text { Selective Optimization with } \\
\text { Compensation Theory (SOC) }\end{array}$ & $\begin{array}{l}\text { Domains are pared down (selection), expectations are adjusted and reserves utilized } \\
\text { (optimization), strategies are then implemented (compensation) by using the mind or } \\
\text { technology [64]. }\end{array}$ \\
\hline $\begin{array}{l}\text { Socioemotional Selectivity } \\
\text { Theory (SST) }\end{array}$ & $\begin{array}{l}\text { Paring down the social network to reflect social priorities, focusing on more } \\
\text { emotionally riveting content due to the perception of limited time left }[48,49] \text {. }\end{array}$ \\
\hline
\end{tabular}

\subsection{Results}

Overall, examples depicting the Activity Theory $(n=62)$ and Gerotranscendence $(n=42)$ were most prominent within the oral history narratives. Surprisingly, notation of SST was minimal $(n=16)$, just above Continuity $(n=14)$, from 230 overall theories noted. Additionally, there were few examples of centenarians actively choosing to disengage from society (Disengagement Theory, $n=27)$. Table 5 shows the key words and ideas used by centenarians that were associated with each theory. It should be noted that in some cases, centenarian narratives were classified under multiple theories. Passages classified as examples of both the Activity and Continuity were the most likely to overlap. 
Table 5. Key words and ideas associated with each theory.

\begin{tabular}{|c|c|c|c|c|c|c|}
\hline Activity Theory & Gerotranscendence Theory & Disengagement Theory & Continuity Theory & Modernization Theory & SOC & SST \\
\hline $\begin{array}{ll}\text { - } & \text { Work } \\
\text { - } & \text { Positive Attitude } \\
\text { - } & \text { Accomplishment } \\
\text { - } & \text { Perseverance } \\
\text { - } & \text { Exercise }\end{array}$ & $\begin{array}{ll}\text { - } & \text { Reflection } \\
\text { - } & \text { Praying } \\
\text { - } & \text { Family } \\
\text { - } & \text { Morals } \\
\text { - } & \text { Values } \\
\text { - } & \text { Death } \\
\text { - } & \text { Purpose }\end{array}$ & $\begin{array}{ll}\text { - } & \text { Disability } \\
\text { - } & \text { Fade out } \\
\text { - } & \text { Monotonous }\end{array}$ & $\begin{array}{ll}\text { - } & \text { Church } \\
\text { - } & \text { Spirituality } \\
\text { - } & \text { Interests } \\
\text { - } & \text { Hobbies } \\
\text { - } & \text { Routines }\end{array}$ & $\begin{array}{ll}\text { - } & \text { Technology } \\
\text { - } & \text { Fast-paced } \\
\text { - } & \text { Changes }\end{array}$ & $\begin{array}{ll}\text { - } & \text { Modifications } \\
\text { - } & \text { Adjustment } \\
\text { - } & \text { Mindset } \\
\text { - } & \text { Adapt } \\
\text { - } & \text { Coping }\end{array}$ & $\begin{array}{ll}\text { - } & \text { Free time } \\
\text { - } & \text { Relationships }\end{array}$ \\
\hline
\end{tabular}




\section{Theories}

\subsection{Activity Theory}

There seemed to be distinct examples of Activity Theory that included physical or socio-cognitive engagements. Many centenarians enjoyed the physical act of chores and/or exercise and felt that such activity may have influenced their longevity. In addition, readily identified were leisure pursuits through a hobby. A total of 62 examples of Activity Theory appeared in the transcripts (Table 6).

Table 6. Theory frequency.

\begin{tabular}{ccc}
\hline Theory & Frequency & Percent \\
\hline Activity Theory & 62 & $26.96 \%$ \\
Theory of Gerotranscendence & 42 & $18.26 \%$ \\
Modernization Theory & 31 & $13.48 \%$ \\
SOC Theory & 27 & $11.74 \%$ \\
Disengagement Theory & 27 & $11.74 \%$ \\
SST & 16 & $6.96 \%$ \\
Continuity Theory & 25 & $10.87 \%$ \\
\hline Total & 230 & $100.0 \%$ \\
\hline
\end{tabular}

\subsection{Physical Activity}

Gardening seemed to be a particularly enjoyable activity for some centenarians. Mr. Hudson stated, "I got the tomato plants out in the greenhouse, and I'll water them until after the first of May, and then I'll put them out. I'll have some early tomatoes." Similarly, Mr. Scott said "Well, the main thing is, you can't be lazy and have a garden like that ... You've got something that needs to be done, get your tail out there and do it ..." Mr. LaFon stated, "A friend and I took the master gardener [courses and were the] first master gardeners in Oklahoma." Ms. Tranchilla felt the need to stay active due to religious reasons: "Well, I just thought the good Lord is keeping me here, so keep active." She also spoke of the importance of physical activity: "I do a lot of exercise. Even now, I have a man that comes in. He's a trainer. He comes twice a week. He gives me a good workout." Ms. Norris also stated that she kept active by maintaining her property. She said, "There's still plenty of yard work out there-flower beds and things." Ms. Norris also stated that she enjoyed physical activity: "I feel good-I feel better when I do some hard work that pulls my muscles and all."

Some centenarians have actively stayed employed in the workforce. Mr. Hopkins stated, "They said 'Ain't you old enough to retire?' I said 'I never really thought about it."' Although many friends and co-workers expressed surprise at this, Mr. Hopkins found his employment to be routine. Ms. Ander stayed employed at her family-owned shoe store, working six days a week. She reported that she rarely missed work: "... Only in ill health. That would hardly ever keep me, because I would crawl to work if I could get there."

It should also be noted that some centenarian comments seemed to indicate that if they stopped being active they might never start again, eluding to the "use it or lose it" phrase that some gerontologists have asserted is beneficial to older adults in late life and often associated with the Activity Theory. For example, Ms. Joyner still pushed herself to play the piano on a daily basis: "Once you quit, you'll not start again. So I try to play a little every day." Ms. Anderson seemed to echo similar remarks when she said, "Do all you can for as long as you can. I think positive. I think what you think is who you are. As a man thinketh, so he is. I'm not lazy, and I like to be busy."

Some centenarians also reflected on how their activity in earlier years may have increased the likelihood that they would live to 100. Mr. Pierson reported that he "[Got] plenty of exercise, because that's no problem out on the farm." Ms. Koelsch also felt that it was possible that her strong work ethic contributed to her longevity: "I liked to work." Mr. Creider also said, "I don't think there is a secret. I think mostly it's just have something to do. Keep busy with something." 
It was also interesting to note that some centenarians still wanted to be active when their family members felt like they should relax a bit. For example, Mr. Creider stated that his daughter "won't let me go get the mail. If I catch her gone, I sneak out there for a minute." Ms. Youngblood also reported, "Well, I get up in the morning and I do all my own chores. I make my bed, dress. I go to the kitchen and I help my daughter."

\subsection{Socio-Cognitive Engagement}

Contrary to what some might believe, some centenarians had very active social lives. For example, Ms. Norris reported that her summer was so busy that "I haven't had time to read." Ms. Tranchilla also demonstrated significant socio-cognitive engagement when she reported, "I do my own taxes."

Ms. Rainwater was not very physically active, but she reported trying to keep up with the news by reading. Ms. Rainwater also said, "I have taught myself a great deal about it" referring to computers. This interest and drive for learning new things did not seem to stop just because of age. The feeling of usefulness also seemed to be of importance to some centenarians. Ms. Koelsch stated, "I have a friend that went to church and she came over one day, and she said, 'I'm going to teach you how to make a rosary.' I said, 'okay.' I got started, and I'm telling you, I really do love to do that. I feel like I've done something." This sentiment was also expressed when Ms. Koelsch stated, "That's one thing in my old age I can keep doing." Mr. Hudson also stated, "Yes. I'm not quitting until the time comes to go. (Laughter) When the good Lord calls, that'll be it."

Overall, many centenarians spoke to the importance of not quitting or giving up, unless forced to do so (in some cases due to health or disability). For example, Mr. Scott said "Work! Listen, don't ever quit work because you're sixty-five. That is no excuse. If you ever quit work, that's wrong."

\subsection{Continuity Theory}

Illustration of Continuity for some centenarians continued through their hobbies and interests. For others, it was how religious and spiritual beliefs were important to them throughout their entire lives. A total of 25 examples were identified in the transcripts. Ms. Culvern said, "... I guess church has just always been a part of my life." Mr. Scott also responded similarly when asked if religion had always been a strong part of his life: "... Church has always been, yeah, yeah." Mr. Hudson was also extremely involved in education throughout his entire life. Although he was no longer involved quite so actively, he still attended some educational meetings.

Other centenarians reported consistency in interests. Ms. Joyner said, "I have books I've read, some of them two times, some of them three times... I get them out and reread them and put them back on the shelf..." Mr. Burke always seemed to have an interest in electrical aspects. As a young child, he mentioned his excitement around "electric lights and batteries." Reflecting on his time as a little boy he said, "A dream I did have was I would be an electrical engineer someday. I got halfway there, not full engineer." Even living in a retirement community, he reported, "there's a residents meeting, which I've been taking care of the audio equipment..."

Daily and weekly routines were also examples of Continuity Theory. Mr. Burke also mentioned some of the activities he was involved with demonstrated continuity. For example, he reported he was involved with singing practice every Monday. Ms. Ander also demonstrated continuity by stating, "I go to McDonald's every morning. I have for twenty years. All I have is coffee and orange juice, and I read my Tulsa paper ... " Continuity Theory helps show the consistency of these individuals throughout their lives. They might be 100, but that does not change that they still possess hobbies and interests. Nevertheless, it also demonstrates their willingness to stay active, which loops back into Activity Theory.

\subsection{Disengagement Theory}

Most of the examples of disengagement dealt with centenarians forced to withdraw socially due to circumstances beyond their control (e.g., disability or living situation). Other examples of withdrawal 
came from a perceived lack of purpose. There was little evidence of centenarians actively choosing to disengage from society. A total of 27 examples of the Disengagement Theory were noted.

Several centenarian comments seemed to indicate a lack of purpose or decreased status within society. Ms. Anderson said "... You slow down. You fade out. You just fade out. It's hard. It's really hard. I don't want to be a hundred and one, but I don't have a choice." Ms. Joyner reported that she did not feel as if her advice or perspective was welcomed. She said, "Well, when you get to be 100, you learn you don't give advice because people don't want it, and you might as well not waste your breath." Mr. Allton also echoed lack of purpose or usefulness when he reported "[A] typical day for me, now? Go eat breakfast, come back home and go to bed, sleep. Get up, eat supper and go back to bed. I don't do anything." His inactivity may have been due to his mobility challenges (as he reported that he had both knees operated on and needed to rest frequently).

Ms. Youngblood's statement about her hearing loss illustrated her frustration with feeling left out of conversations, as well as disengagement due to hearing impairment. She said "The only thing right now that bothers me is the fact that I'm losing my hearing. That bothers me because I know I'm missing a lot with my children. They get around here, the bunch of them, and they yak yak yak yak and I can't understand what they're talking about."

Ms. Koelsch also discussed how her decreased mobility interfered with her ability to attend church. She said, " ... Well right now I haven't been [to church] because of my knees. It's hard to make it, but I've tried. I'm going to, I hope for Easter." Ms. Vandaveer voiced similar perspectives: "I haven't been going too much [to church] because I don't hear a thing that's going on, and I'm ashamed of myself."

Ms. Joyner seemed to demonstrate the relinquishing of roles to the younger generation when she explained that she rarely plays the organ at church: "They have a regular organist. Only when she is gone or stuck or suddenly there is an emergency, I can play the organ. My feet still know how to move to play the organ, so we get it done." Some centenarians talked about giving up specific roles in the near future (if they had not done so already). Ms. Culvern stated, "... I'm not going to drive much longer. I don't mind driving. I don't seem to have any problem about it. My biggest problem is walking from here down to the street down there where my car is."

One centenarian who lived in long-term care also voiced a certain level of disengagement. Mr. Scott said, "... I'll get in bed and she'll cover me up ... I can't even have a conversation. The people that work here are busy." This statement again seemed to indicate Mr. Scott's disengagement was a result of his living situation rather than active disengagement from society. Overall, it appeared most centenarians were not actively choosing to withdraw from society.

\subsection{Theory of Gerotranscendence}

Religion and spirituality were two important aspects to many centenarians when they reflected on their lives. The Great Depression may have also influenced their strong work ethic and sense of responsibility. Researchers identified a total of 42 examples of Gerotranscendence in the transcripts.

Mr. LaFon stated that he desired time for reflection. He said, "I try to have quiet time, but sometimes it gets sort of neglected." Ms. Tranchilla also echoed the importance of quiet, reflective time: " ... I pray every morning for about an hour." Ms. Vandaveer also seemed to reflect on her family when she could not sleep: " ... Sometimes I lay there and don't sleep. I get to thinking about my grandkids, nieces, nephews ... " Reflection at times also included thoughts on morals, values, and choices they made throughout life (depicting evidence of the Theory of Gerotranscendence). Mr. Scott stated "Well, my main thing is to live a good Christian life. Live a good life. Don't run around. Listen, you are looking at a one-woman man. I never trifled on my wife not even one time, and when we was going together, she'd slap your face. I'm a one-woman man. Now, you know what I'm talking about."

Ms. Rainwater stated, "All I say is live a good, clean life. To me, that is the key to all of it, is just to live a good, clean life and do all that you can for other people." Mr. Pierson said, "Number one, let God be your guide. I haven't followed him every time, but that was the main thing. Live close to the Lord, and when you're wrong, admit it." Mr. Jackson also talked about the importance of spirituality and religion when he 
said, "That's the only secret. Trust in God. Do right. Treat everybody right. Black, white or whatever. Treat everybody right."

Throughout the transcripts, centenarians reflected on responsibility and ownership over life choices. For example, Ms. Rainwater said, " .. I've always had a feeling that you got to look out for yourself and you got to plan ahead and things like that. So many people wait until an emergency comes, and they don't know what to do."

Some centenarians engaged in significant reflection about the meaning of their lives, particularly as it related to living through difficult times. For example, Ms. Vandaveer said "Well, I had a hard life, I can say that, but I'm glad that I lived the way that I lived it. It taught you a lot about life. There was parts of it I wish I never had to go through, but as I said, I think it's been easier for me to lose them, because I've always felt that's part of what we was here for. We can't live forever."

There seemed to be little fear of death among centenarians. Ms. Youngblood in particular seemed to be at peace with the thought of her own mortality. She said, "But that's life, you know. I'm ready. I am. When I go, I go. I just want to go quietly." Mr. Allton also said, "I'm ready to go any time he [the Lord] is ready. When he gets ready for me, he'll call me. Not until ... so I take it one day at a time."

Although centenarians talked about how they were ready for death, they still felt as though their remaining days should have purpose. Mr. Burke felt as though he still had a purpose with his remaining time alive. He said "Every now and then I think about that because people ask, like you are, and I say, 'Well, God puts us here for some purpose that he wants us to accomplish,' and I guess I haven't accomplished mine yet. That's on God's timetable."

\subsection{Modernization Theory}

Most of the modernization examples noted in the transcripts related to technological development. The development and advancement of technology affected the older adults who were still working. Additionally, some of the centenarians expressed concern that their values, practices, morals were not applicable in today's world. Analysis of the transcripts revealed a total of 31 examples of Modernization Theory.

Mr. Allton said, "Oh, lord. All these new-fangled gadgets they have" was one of the biggest changes he had seen during his lifetime. Mr. Burke also indicated, "[Technology] moves so fast you can't catch up with it." Ms. Joyner also reported that today's society is a "different world" due to the technological changes. Ms. Ander spoke about the difficulty of continuing to work in her family shoe store while competing against bigger retailers. She said, "Honey, it's a different world today. It's too hard. It's too hard. I can't cope with all of them anymore. I feel left out. I'm left out." Ms. Ander also went on to discuss how business practices are much different today. She said, "... We are on credit cards. The girls take care of those. I don't have much to do with those. I don't think I could handle it." Mr. LaFon also spoke about his career in medicine would be different today. He said, "Medicine has changed entirely, you know. The electrocardiograph, we didn't have that to start with. The first three or four years of my practice, we didn't have cardiographs."

Ms. Anderson also talked about how life today is much more complicated due to the fast-paced nature. She said, "Yes, but back in those days it was slow. Today it's so fast I can't even keep up with the days, but back then you were relaxed. It's a happy life. It was hard, but it was happy ... "Ms. Joyner's comments seemed similar when she mentioned that values and goals are different today. "Things change. People don't have the same goals that they used to have, the same ideals they used to have. They have things they want to do, but it is just not quite the same."

\subsection{Selective Optimization with Compensation (SOC)}

Living through difficult times (e.g., the Great Depression and Dust Bowl) seemed to help prime centenarians to deal with future challenges. They were able to adapt their expectations to cope with future life events. Other examples included health and disability issues that caused centenarians 
to have to interact with their environment differently. SOC occurred a total of 27 times throughout the transcripts.

Ms. Rainwater reported that even though she struggled to see, she still tried to read the newspaper. "I got my Stillwater paper this morning, and I can't read, only just the big headlines." Although she would still like to read the entire newspaper, she compensated by reading the stories shown in larger font. Mr. Creider also talked about how he compensated by using a magnifying glass to read the paper. He said, "I'm getting now to where all I read is the headlines ... " Mr. Hopkins said, "I have arthritis in my shoulders and hands but I don't let that stop me. I keep on moving. I do my thing." Mr. Burke said he no longer drives and that he compensates by relying on others, "I have to depend on other people to take me now." Ms. Koelsch's family member also talked about how she cooks differently due to her limited eyesight. She said, "... Now, she sticks her finger down in there, and she feels the heat come on, and then she'll go ahead and turn it [stove] on." Mr. Hudson talked about how his forms of entertainment look different due to his poor eyesight and hearing. Instead, he plays dominoes to keep himself busy.

Overall, centenarians did not see the sense in dwelling on negative aspects of life. There was consensus among centenarians that if something could not change, it was better to adjust and make due rather than dwelling on the negative. Ms. Culvern said, "Just enjoy as things come along, I guess. Take them in stride. I did have one period there during the Depression era that was a pretty sad time, but you get over those things and go on. Do the best you can." Ms. Tranchilla also spoke of the challenges she encountered when living with her in-laws as a newlywed. However, she said, "... But I didn't dwell on it, though. I just made the best of it ..." "Ms. Youngblood also talked about making the best of things during difficult times when she said, "I just took what, you know, that come along. I either knocked it down or lived with it." Moving at age 83 was a significant challenge for Ms. Tranchilla. She said, "Anyway, I sometimes miss St. Louis. But that's okay. That's the way I am. I just make the best of it."

The various challenges (Great Depression, Dust Bowl, farming, and/or hunger) many centenarians experienced as children gave them early skills in compensation. As an example, Mr. Hopkins spoke of the challenges related to hunger when he was growing up. He seemed to compensate through humor when recalling this memory. He said, "Back then, we didn't know what lunch was." Ms. Ander also spoke of the need for compensating when it came to growing up during difficult financial times. She said, "... I didn't even have a dress to wear. I had to wear my oldest sister's dress under my gown to graduate. I didn't go to the junior/senior banquet. We couldn't afford anything. We were just lucky to have meals and get to school to graduate."

\subsection{Socioemotional Selectivity Theory (SST)}

Within the transcripts, prioritizing family and being more selective about which activities to engage in were examples of SST. Analysis found a total of 16 examples of SST. Some centenarians demonstrated SST during their retirement years. For example, Mr. Allton seemed to have increased time to devote to activities that he liked such as traveling, fishing, and breakfast with friends. Ms. Norris seemed to appreciate the close connection she had with her neighbors. She said "... Then in 2000, my husband passed away and I'm still here. I've had a lot of-especially two good neighbors after moving in here." Ms. Culvern spoke of the close relationship she had with her sister. She said "...Well of course we grew up together. But, I think we became more bonded when we were going to school in Denver." Mr. LaFon also prioritized his family and even planned so that he would be able to provide financial support to them even after he died. Lastly, for many centenarians, religion and spirituality were crucial components of their lives. Goals and values often followed those practices.

\subsection{Gender Differences}

Assessing gender differences among the theories gave interesting results; see Table 7 for specifics. Overall, theory examples were more likely to be identified in women than men. Women were more likely to endorse Activity, Modernization, SST, SOC, Disengagement and the Theory of Gerotranscendence. However, Continuity Theory was slightly more likely to be identified in men. 
Table 7. Gender differences.

\begin{tabular}{|c|c|c|}
\hline & Female & Male \\
\hline & Activity & Activity \\
\hline Individual Identification & 9 & 9 \\
\hline \multirow[t]{2}{*}{ Added Examples among Participants } & 35 & 27 \\
\hline & Modernization & Modernization \\
\hline Individual Identification & 9 & 8 \\
\hline \multirow[t]{2}{*}{ Added Examples among Participants } & 17 & 14 \\
\hline & SST & SST \\
\hline Individual Identification & 9 & 5 \\
\hline \multirow[t]{2}{*}{ Added Examples among Participants } & 11 & 5 \\
\hline & SOC & SOC \\
\hline Individual Identification & 9 & 7 \\
\hline \multirow[t]{2}{*}{ Added Examples among Participants } & 16 & 11 \\
\hline & Disengagement & Disengagement \\
\hline Individual Identification & 10 & 7 \\
\hline \multirow[t]{2}{*}{ Added Examples among Participants } & 18 & 9 \\
\hline & Gerotranscendence & Gerotranscendence \\
\hline Individual Identification & 8 & 7 \\
\hline \multirow[t]{2}{*}{ Added Examples among Participants } & 25 & 17 \\
\hline & Continuity & Continuity \\
\hline Individual Identification & 4 & 5 \\
\hline Added Examples among Participants & 11 & 14 \\
\hline
\end{tabular}

\section{Discussion}

The purpose of this study was to assess evidence of psychosocial theories of aging within oral history narratives. The main finding of this study showed that most centenarians were extremely active and engaged. Therefore, the Activity Theory was the most prominent psychosocial theory noted within the transcripts. In most instances, it was only in cases of impairment or disability that a centenarian disengaged from society. Surprisingly, there was little evidence of SST within the transcripts. These findings add to the understanding of how psychosocial theories of aging apply to the oldest-old and centenarians. However, it is important to keep in mind that the centenarians who were interviewed were, for the most part, very active. Therefore, this survivor bias may have skewed the theoretical findings noted in the narratives.

Even the small act of tending to a garden or tomato plant give some centenarians purpose. Previous research has noted the protective effect a sense of purpose has against mortality [64]. Wang and Leng [65] found that gardening was especially beneficial to older adults with mobility impairments by greatly reducing the likelihood of mortality. Treasuring a sense of purpose may also be one of the reasons why two centenarians were still working full-time. These centenarians did not let their age stop them even though the "traditional" retirement age had passed several decades ago. In addition, research by Dendinger et al. [66] noted that the benefits of generativity (passing on skills and abilities to future generations) might be one of the reasons why older adults continue working well into older adulthood.

The most common examples of Continuity Theory referred to routines or habits regarding religious service attendance and using religion or spirituality as a guide throughout life. Most centenarians grew up attending church regularly and living a life in accordance with church teachings. It seemed that relying on religion and spirituality especially during difficult times was a useful coping technique. These findings are similar to other research that noted centenarians often rely on religion when coping with stressful situations [67]. Some critics of the Continuity Theory argue that 
it has far more applicability to healthy older adults. Although this may be true, centenarians in this study found ways to continue participation in interests and hobbies despite some health challenges (e.g., instead of attending church on a regular basis, praying or bible reading may have been prioritized). It was also apparent that much of what centenarians shared seemed to be related to social continuity (i.e., not wanting to be left behind in social activities and experiences). That may have been one of the motivating factors for continuing engagement in religious activities, eating out, etc. Perhaps some of these behaviors are a reflection of our individualistic society. It is possible that some centenarians perceive exclusion and therefore make a more concerted effort to maintain social continuity. Some researchers have discussed disengagement from activities as a natural progression [68]. However, none of the centenarians interviewed actively chose to disengage from society by choice. In some cases, centenarians seemed to indicate disengagement was the result of feeling their opinion or advice was undervalued. In many other cases, a disability or impairment (e.g., vision or hearing impairment or decreased mobility) forced centenarians to disengage. In one case, disengagement was a factor of a centenarian's living situation (e.g., living in a retirement community where he perceived the staff to be too busy to engage in conversation). Perhaps inclusion and shift of focus on inadvertent disengagement outside the control or wishes of older adults may strengthen the Disengagement Theory. Likewise, we also wonder if disengagement should broaden to neurocognitive realms (dementia, Alzheimer's, medication use, etc ... ). However, it should be noted that the Disengagement Theory is not used in recent gerontological research. In addition, it seemed that advances and changes in society (eluded to with Modernization Theory), made it difficult for some centenarians to feel as though they fit in. This is not surprising given that the world has changed significantly in the span of 100 years. As Xie and Bugg [69] pointed out, older adults are at risk of being left behind when it comes to technological advancements. It is not surprising then that some older adults reported difficulty keeping up with all of the changes related to technology.

Researchers noted a great deal of gerotranscendence evidence within the transcripts. Gondo [7] described gerotranscendence as a gradual yet adaptive change that allows older adults to maintain higher levels of psychological well-being. In this study, centenarians expressed little if any regret about how they lived their lives. When reflecting on their lives, most reported that they had lived a good life despite living through some very significant historical challenges. It is noteworthy that none of the centenarians reported worrying or dwelling on small stressors. Perhaps the challenges they faced earlier in life allowed them to develop useful coping strategies, which continue to be useful in late adulthood.

It is not surprising that centenarians spent substantial time praying, thinking about family, and reflecting on life events and choices. Tornstam [34] indicated that reflecting and pondering about life are two of the prime examples depicting gerotranscendence. It was intriguing that many centenarians reflected they should be appreciative of being alive and continue striving for their best and work hard until their time was up. These findings are similar to research conducted by [70] who reported participating in regular activities is associated with gerotranscendence. Overall, it seemed centenarians tried to find meaning and purpose each day. Sometimes, that purpose came through attending church or practicing religion, while for others it rested on reflecting on their life. Generally, many of the individuals seemed to turn their thinking inward. This seems to be related to what Tornstam [34] described as changing priorities to more cosmic and spiritual matters. These findings may also add to our understanding of the gerotranscendence or at least build on this theory. For example, throughout the oral history interview centenarians were reflecting on their lives and discovered aspects of themselves that they had not considered or reflected on before the interview. In that sense, this research provides additional evidence for Tornstam's [71] work on the self-confrontation element of gerotranscendence with older adults. Relatedly, many centenarians reported great difficulty and challenges throughout their lives, most seemed to transcend any negative feelings about the obstacles. Instead, focusing on what they learned from such experiences and how it ultimately shaped their lives. 
The Selective Optimization with Compensation model discusses two types of selection (e.g., elective selection (choosing new goals to focus on) and loss-based selection (altering goals due to loss or decline) [7]. There were specific examples of loss-based selection noted in the transcripts. Some centenarians had to alter or change their goals to reflect their abilities (e.g., changing the way they read the newspaper). However, there was also evidence of centenarians focusing on choosing new goals rather than dwelling on stressors and challenges; they seemed to overcome negatives with relative ease.

Although some centenarians had slowed down, they tried to optimize their own abilities with functioning, perception, and overall outlook on life. To an outsider, it may seem as though the oldest-old and centenarians are less capable than they used to be. However, there was significant evidence that centenarians pushed themselves to do more and stay engaged. In this way, they were optimizing their aging experience.

It is interesting that the analyzed oral history narratives provided little evidence of Socioemotional Selectivity Theory (SST). While the paring down of social networks may apply to the young-old or middle-old; perhaps, it is not as true for the oldest-old. As previous research has noted, one does not become old alone. It is only through significant support that one reaches this status. It is also possible that centenarians do engage in Socioemotional Selectivity, though it is not identified in the transcripts or specific examples of it did not arise during the interview. We agree withCornwell et al. [72] who advocate for additional social gerontology research assessing older adult social networks. To our knowledge, very little research on analyzing the social networks of centenarians and the oldest-old has taken place. It is possible that had more quantitative methods been employed to analyze the social networks, we may have seen the smaller network sizes that Carstensen et al. [49] report is typical of older adults. However, we may be able to understand a bit more about socioemotional selectivity by analyzing it through Carstensen's temporal horizon perspective [73]. From this perspective, with decreasing time horizons, older adults are more focused on prioritizing their emotional well-being as a result of their perception of limited time. This may also be one of the reasons why we saw more evidence of Activity and Continuity Theories. It is possible that these older adults had always been active and continued to maintain these interests, hobbies, etc. in order to prioritize their own emotional well-being.

Centenarian research tends to be focused on women, as women outlive men in older adulthood. Therefore, in some instances, research findings are more applicable to women. However, this study attempted to account for those differences by including similar numbers of men and women. Without taking this into consideration, research on the oldest-old is mostly focused on women. As Moen [74] discussed, gender has a significant impact on the roles one takes on as well as the duration of such roles. Therefore, it is important to understand the experiences of both men and women.

Although in many cases centenarians had dealt with significant losses, discussion surrounding such losses did not seem to be a focus for many of the interviewees. Although this is surprising, as the centenarians lived through very difficult historical times (e.g., the Great Depression and the Dust Bowl), it is possible that they were more focused on maintaining their emotional well-being and chose not to ruminate on these events. It is also possible that the centenarians may have thought the interviewers did not want to hear about such losses and therefore decided to focus on more positive events.

Similar to points made by Clarke and Warren [75], we find it intriguing that many public policies do not take into account how active older adults are (and in this study, the oldest-old). Given that so many centenarians are relatively independent, should there be more resources made available to them to age in place in their own homes? Should the Family Medical Leave Act be revised to allow family members an easier way to provide care to aging parents? Lastly, revamping the Social Security system is also of importance as longevity increases and we see more and more centenarians in society. 


\section{Conclusions}

Similar to Poon et al. [5], these findings suggest that health may be a critical factor during later adulthood. However, as Poon pointed out, psychosocial factors also assist in our understanding of longevity and have been largely overlooked when compared to research on the biomedical aspects. This paper contributes to known psychosocial factors of aging and longevity. Most centenarians continued to be as active as they could for as long as they could. It was evident that many of the challenging experiences centenarians dealt with growing up impacted their survivorship. For some centenarians it seemed that they had already lived through the most difficult part of their lives, so any other obstacles paled in comparison. For others, it seemed their constant compensation skills and mindset of trying to make the best out of the situation (optimization) assisted in adjusting to older adulthood. Interestingly, this may connect with discussions of stoicism eluded to in other centenarian studies [10]. It seems centenarians did not think complaining or wallowing in their troubles would do any good. Little energy was devoted to worrying or trying to change something unchangeable. The strong spirit and grit evidenced in the transcripts may serve as a protective mechanism in older adulthood. The prominent evidence of the Activity Theory indicates that life at 100 years of age is not always depressing, bleak, or without meaning and purpose.

\section{Limitations and Future Research}

Interviewer questions did not specifically assess psychosocial theories of aging. With specifically focused questions, it is possible that the findings would have been different. Although there was little evidence of the Socioemotional Selectivity Theory and Disengagement Theory noted within the transcripts, other researchers might have noted different examples. It is also possible that centenarians may have been less likely to discuss instances when they withdrew from activities or relationships as choosing to do so may be perceived negatively (i.e., giving up or weakness). Consequently, under-reporting may be one of the reasons why there is so little evidence of Socioemotional Selectivity or Disengagement Theories. Additionally, other researchers may have identified other theory examples not identified in this research study. Theory difference amongst genders may come from gender factors themselves, but also the identification done by the researchers. Although multiple researchers selected and reviewed examples of each theory, researcher subjectivity is a limitation. Although a subset of 20 oral history narratives were assessed, the relatively low number is a limitation. If additional narratives had been examined, it is possible that there could have been further evidence in support or opposition of the theories.

Centenarians who participated in this research study were also fairly healthy and cognitively intact. Consequently, they may not represent the normative trajectory of longevity. The prominent examples of some of the psychosocial theories (e.g., Activity Theory) may also be due to culture. Therefore, these findings may not be generalizable to other centenarians residing in other locations.

Limited neuropsychological examination is also a limitation. Although the purpose of this project was not to conduct an extensive neuropsychological examination, it would be interesting to assess how these processes may mediate and moderate content within narrative oral storytelling in future research.

Future research should also consider finding "evidence" of other theories of aging not analyzed within this study. For example, do the typical psychological, sociological theories of aging taught in gerontology classes apply to the oldest-old or are they too excluded from analysis? It would also be interesting to assess evidence of psychosocial theories in other centenarians outside of Oklahoma.

Acknowledgments: Funding for covering the cost of this publication was supported by the Oklahoma State University Bryan Close Endowed Professorship in Adulthood and Aging. We would like to acknowledge the Oklahoma State University Library's Oklahoma Oral History Research Program (OOHRP). The centenarian narratives from the Oklahoma 100 Year Life Oral History Project are available online by visiting: https:/ / www. library.okstate.edu/oralhistory/digital/100/. 
Author Contributions: Alex J. Bishop and Tanya Finchum conceived and methodologically designed this collaborative project. Melinda Heinz and Grace da Rosa were invited as experts to qualitatively analyze transcribed oral history content for evidence of psychosocial theories of aging. Melinda Heinz also contributed by writing the paper. Nicholas Cone assisted in qualitative analysis and writing the paper. Tanya Finchum contributed expertise and written contribution pertaining to the collection of oral history interviews, transcription and auditing of completed oral history narratives, and the interpretation of results. Alex J. Bishop contributed expertise and written detail pertaining to age verification procedures, sampling methodological procedures, and theoretical interpretation and discussion of results and future research.

Conflicts of Interest: The authors declare no conflict of interest.

\section{References}

1. De Grey, A.; Rae, M. Ending Aging: The Rejuvenation Breakthroughs that Could Reverse Human Aging in Our Lifetime, 1st ed.; St. Martin's Press: New York, NY, USA, 2007; p. 389.

2. Perls, T. Understanding the determinants of exceptional longevity. Ann. Intern. Med. 2003, 139, 445-449. [CrossRef] [PubMed]

3. Hjelmborg, J.V.; Iachine, I.; Skytthe, A.; Vaupel, J.W.; McGue, M.; Koskenvuo, M.; Kaprio, J.; Pedersen, N.L.; Christensen, K. Genetic influence on human lifespan and longevity. Hum. Genet. 2006, 119, 312-321. [CrossRef] [PubMed]

4. Ljungquist, B.; Berg, S.; Lanke, J.; McClearn, G.E.; Pedersen, N.L. The effect of genetic factors for longevity: A comparison of identical and fraternal twins in the swedish twin registry. J. Gerontol. Ser. A Biol. Sci. Med. Sci. 1998, 53A, M441-M446. [CrossRef]

5. Poon, L.W.; Martin, P.; Bishop, A.; Cho, J.; da Rosa, G.; Deshpande, N.; Hensley, R.; MacDonald, M.; Margrett, J.; Randall, G.K.; et al. Understanding centenarians' psychosocial dynamics and their contributions to health and quality of life. Curr. Gerontol. Geriatr. Res. 2010, 2010,1-13. [CrossRef] [PubMed]

6. Silverstein, M.; Bengtson, V.L.; Putney, N.M.; Gans, D. Theories about age and aging. In Handbook of Theories of Aging; Silverstein, M., Bengtson, V.L., Putney, N.M., Gans, D., Eds.; Springer Publishing Company: New York, NY, USA, 2009; pp. 3-24.

7. Gondo, Y. Longevity and successful ageing: Implications from the oldest old and centenarians. Asian J. Gerontol. Geriatr. 2012, 7, 39-43.

8. Vaupel, J.W. Biodemography of human ageing. Nature 2010, 464, 536-542. [CrossRef] [PubMed]

9. Olshansky, S.J.; Goldman, D.P.; Zheng, Y.; Rowe, J.W. Aging in america in the twenty-first century: Demographic forecasts from the macarthur foundation research network on an aging society. Milbank $Q$. 2009, 87, 842-862. [CrossRef] [PubMed]

10. Carnes, B.A.; Olshansky, S.J.; Hayflick, L. Can human biology allow most of us to become centenarians? J. Gerontol. Ser. A Biol. Sci. Med. Sci. 2012, 68, 136-142. [CrossRef] [PubMed]

11. Hutnik, N.; Smith, P.; Koch, T. What does it feel like to be 100? Socio-emotional aspects of well-being in the stories of 16 centenarians living in the United Kingdom. Aging Ment. Health 2012, 16, 811-818. [CrossRef] [PubMed]

12. Reichstadt, J.; Sengupta, G.; Depp, C.A.; Palinkas, L.A.; Jeste, D.V. Older adults' perspectives on successful aging: Qualitative interviews. Am. J. Geriatr. Psychiatry 2010, 18, 567-575. [CrossRef] [PubMed]

13. Baum, W. Therapeutic value of oral history. Int. J. Aging Hum. Dev. 1980, 12, 49-53. [CrossRef] [PubMed]

14. Collins, M.; Bloom, R. The role of oral history in accounting. Account. Audit. Account. J. 1991, 4. [CrossRef]

15. Thomson, A. Fifty years on: An international perspective on oral history. J. Am. Hist. 1998, 85, 581-595. [CrossRef]

16. Butler, R.N. The life review: An interpretation of reminiscence in the aged. In New Thoughts on Old Age; Kastenbaum, R., Ed.; Springer: New York, NY, USA, 1964; pp. 265-280.

17. Bishop, A.J.; Martin, P.; Poon, L. Happiness and congruence in older adulthood: A structural model of life satisfaction. Aging Ment. Health 2007, 10, 445-453. [CrossRef] [PubMed]

18. Bishop, A.J.; Martin, P.; MacDonald, M.; Poon, L. Predicting happiness among centenarians. Gerontology 2010, 56, 88-92. [CrossRef] [PubMed]

19. Bishop, A.J.; Martin, P.; Poon, L.; Johnson, M.A. Exploring positive and negative affect as key indicators of life satisfaction among centenarians: Does cognitive performance matter? J. Aging Res. 2011, 2011, 1-10. [CrossRef] [PubMed] 
20. Schroots, J.J.F. Theoretical developments in the psychology of aging. Gerontologist 1996, 36, 742-748. [CrossRef] [PubMed]

21. Cavan, R.S.; Burgess, E.W.; Havighurst, R.J.; Goldhamer, H. Personal Adjustment in Old Age; Science Research Associates, Inc.: Oxford, UK, 1949.

22. Havighurst, R.J.; Albrecht, R. Older People; Longmans, Green: Oxford, UK, 1953.

23. Knapp, M.R.J. The activity theory of aging an examination in the english context. Gerontologist 1977, 17, 553-559. [CrossRef] [PubMed]

24. Diggs, J. Encyclopedia of Aging and public Health; Loue, S.J.D., Sajatovic, M., Eds.; Springer Science + Business Media, LLC: Boston, MA, USA, 2008.

25. Menec, V.H. The relation between everyday activities and successful aging: A 6-year longitudinal study. J. Gerontol. Ser. B Psychol. Sci. Soc. Sci. 2003, 58, S74-S82. [CrossRef]

26. Atchley, R.C. A continuity theory of normal aging. Gerontologist 1989, 29, 183-190. [CrossRef] [PubMed]

27. Franklin, N.C.; Tate, C.A. Lifestyle and successful aging: An overview. Am. J. Lifestyle Med. 2008, 3, 6-11. [CrossRef]

28. Nimrod, G.; Kleiber, D. Reconsidering change and continuity in later life: Toward an innovation theory of successful aging. Int. J. Aging Hum. Dev. 2007, 65, 1-22. [CrossRef] [PubMed]

29. Cumming, E.; William, E.H. Growing Old, the Process of Disengagement; Basic Books: New York, NY, USA, 1961.

30. Adelmann, P.K. Multiple roles and psychological well-being in a national sample of older adults. J. Gerontol. 1994, 49, S277-S285. [CrossRef] [PubMed]

31. Utz, R.L.; Carr, D.; Nesse, R.; Wortman, C.B. The effect of widowhood on older adults' social participation: An evaluation of activity, disengagement, and continuity theories. Gerontologist 2002, 42, 522-533. [CrossRef] [PubMed]

32. Tallmer, M.; Kutner, B. Disengagement and the stresses of aging. J. Gerontol. 1969, 24, 70-75. [CrossRef] [PubMed]

33. Maddox, G.L., Jr. Disengagement theory: A critical evaluation. Gerontologist 1964, 4, 80-82.

34. Tornstam, L. Gerotranscendence: A Developmental Theory of Positive Aging; Springer: New York, NY, USA, 2005.

35. Tornstam, L. Gerotranscendence and the functions of reminiscence. J. Aging Identity 1999, 4, $155-166$. [CrossRef]

36. Dalby, P. Is there a process of spiritual change or development associated with ageing? A critical review of research. Aging Ment. Health 2006, 10, 4-12. [CrossRef] [PubMed]

37. Wang, J.-J.; Lin, Y.-H.; Hsieh, L.-Y. Effects of gerotranscendence support group on gerotranscendence perspective, depression, and life satisfaction of institutionalized elders. Aging Ment. Health 2011, 15, 580-586. [CrossRef] [PubMed]

38. Jewell, A.J. Tornstam's notion of gerotranscendence: Re-examining and questioning the theory. J. Aging Stud. 2014, 30, 112-120. [CrossRef] [PubMed]

39. Cowgill, D.O.; Holmes, L.D.; Cowgill, D.O. Aging and Modernization; Appleton-Century-Crofts: New York, NY, USA, 1972.

40. Rhoads, E.C. Reevaluation of the aging and modernization theory: The samoan evidence. Gerontologist 1984, 24, 243-250. [CrossRef] [PubMed]

41. Bengtson, V.L.; Dowd, J.J.; Smith, D.H.; Inkeles, A. Modernization, modernity, and perceptions of aging: A cross-cultural study. J. Gerontol. 1975, 30, 688-695. [CrossRef] [PubMed]

42. Silverstein, M.; Burholt, V.; Wenger, G.C.; Bengtson, V.L. Parent child relations among very old parents in wales and the United States: A test of modernization theory. J. Aging Stud. 1998, 12, 387-409. [CrossRef]

43. Aboderin, I. Modernization and ageing theory revisited: Current explanations of recent developing world and historical Western shifts in material family support for older people. Ageing Soc. 2004, 24, 29-50. [CrossRef]

44. Achenbaum, W.A.; Stearns, P.N. Old age and modernization. Gerontologist 1978, 18, 307-312. [CrossRef] [PubMed]

45. Baltes, P.B.; Baltes, M.M. Successful Aging: Perspectives from the Behavioral Sciences; Cambridge University Press: Cambridge, UK, 1993.

46. Gignac, M.A.; Cott, C.; Badley, E.M. Adaptation to disability: Applying selective optimization with compensation to the behaviors of older adults with osteoarthritis. Psychol. Aging 2002, 17, 520-524. [CrossRef] [PubMed] 
47. Hahn, E.A.; Lachman, M.E. Everyday experiences of memory problems and control: The adaptive role of selective optimization with compensation in the context of memory decline. Aging Neuropsychol. Cognit. 2014, 22, 25-41. [CrossRef] [PubMed]

48. Ouwehand, C.; de Ridder, D.T.D.; Bensing, J.M. A review of successful aging models: Proposing proactive coping as an important additional strategy. Clin. Psychol. Rev. 2007, 27, 873-884. [CrossRef] [PubMed]

49. Carstensen, L.L.; Isaacowitz, D.M.; Charles, S.T. Taking time seriously: A theory of socioemotional selectivity. Am. Psychol. 1999, 54, 165-181. [CrossRef] [PubMed]

50. Lockenhoff, C.E.; Carstensen, L.L. Socioemotional selectivity theory, aging, and health: The increasingly delicate balance between regulating emotions and making tough choices. J. Personal. 2004, 72, 1395-1424. [CrossRef] [PubMed]

51. Lang, F.R. Regulation of social relationships in later adulthood. J. Gerontol. Ser. B Psychol. Sci. Soc. Sci. 2001, 56, P321-P326. [CrossRef]

52. Lansford, J.E.; Sherman, A.M.; Antonucci, T.C. Satisfaction with social networks: An examination of socioemotional selectivity theory across cohorts. Psychol. Aging 1998, 13, 544-552. [CrossRef] [PubMed]

53. Fung, H.H.; Carstensen, L.L. Motivational changes in response to blocked goals and foreshortened time: Testing alternatives to socioemotional selectivity theory. Psychol. Aging 2004, 19, 68-78. [CrossRef] [PubMed]

54. Urry, H.L.; Gross, J.J. Emotion regulation in older age. Curr. Dir. Psychol. Sci. 2010, 19, 352-357. [CrossRef]

55. U.S. Census Bureau. The American Indian and Alaska Native Population: 2010. Available online: https: / / www.census.gov/prod/cen2010/briefs/c2010br-10.pdf (accessed on 11 April 2017).

56. Folstein, M.F.; Folstein, S.E.; White, T.; Messer, M.A. Mmse-2: Mini-Mental State Examination User's Manual, 2nd ed.; PAR, Inc.: Lutz, FL, USA, 2010.

57. Leonard, W.P.; Jazwinski, M.; Green, R.C.; Woodard, J.L.; Martin, P.; Rodgers, W.L.; Johnson, M.A.; Hausman, D.; Arnold, J.; Davey, A.; et al. Methodological considerations in studying centenarians: Lessons learned from the Georgia centenarian studies. Annu. Rev. Gerontol. Geriatr. 2007, 27, 231-264.

58. Chen, K.; Baek, M.J.; Kim, K.; Park, Y.H.; Kim, S. The validity and reliability of the mini-mental state examination-2 for detecting mild cognitive impairment and alzheimer's disease in a korean population. PLoS ONE 2016, 11, e0163792. [CrossRef]

59. Holtsberg, P.A.; Poon, L.W.; Noble, C.A.; Martin, P. Mini-mental state exam status of community-dwelling cognitively intact centenarians. Int. Psychogeriatr. 1995, 7, 417-427. [CrossRef] [PubMed]

60. Merriam, S.B. Qualitative Research: A Guide to Design and Implementation; Jossey-Bass: San Francisco, CA, USA, 2009.

61. Dilworth-Anderson, P.; Cohen, M.D. Theorizing across cultures. In Handbook of Theories of Aging; Silverstein, M., Bengtson, V.L., Putney, N.M., Gans, D., Eds.; Springer: New York, NY, USA, 2009; pp. 487-498.

62. Poulain, M. On the age validation of supercentenarians. In Supercentenarians; Springer: Berlin/Heidelberg, Germany, 2010; pp. 3-30.

63. Elo, S.; Kyngäs, H. The qualitative content analysis process. J. Adv. Nurs. 2008, 62, 107-115. [CrossRef] [PubMed]

64. Boyle, P.A.; Barnes, L.L.; Buchman, A.S.; Bennett, D.A. Purpose in life is associated with mortality among community-dwelling older persons. Psychosom. Med. 2009, 71, 574-579. [CrossRef] [PubMed]

65. Wang, J.-D.; Lêng, C.H. Daily home gardening improved survival for older people with mobility limitations: An 11-year follow-up study in Taiwan. Clin. Interv. Aging 2016, 11, 947-959. [CrossRef] [PubMed]

66. Dendinger, V.M.; Adams, G.A.; Jacobson, J.D. Reasons for working and their relationship to retirement attitudes, job satisfaction and occupational self-efficacy of bridge employees. Int. J. Aging Hum. Dev. 2005, 61, 21-35. [CrossRef] [PubMed]

67. Martin, P. Personality and coping among centenarians. In Annual Review of Gerontology E Geriatrics; Poon, L.W., Perls, T.T., Eds.; Springer: New York, NY, USA, 2008; Volume 27, pp. 89-106.

68. Cumming, E.; Dean, L.R.; Newell, D.S.; McCaffrey, I. Disengagement-A tentative theory of aging. Sociometry 1960, 23, 23-35. [CrossRef]

69. Xie, B.; Bugg, J.M. Public library computer training for older adults to access high-quality internet health information. Libr. Inf. Sci. Res. 2009, 31, 155-162. [CrossRef] [PubMed]

70. Wang, K.; Duan, G.-X.; Jia, H.-L.; Xu, E.-S.; Chen, X.-M.; Xie, H.-H. The level and influencing factors of gerotranscendence in community-dwelling older adults. Int. J. Nurs. Sci. 2015, 2, 123-127. [CrossRef]

71. Tornstam, L. Maturing into gerotranscendence. J. Transpers. Psychol. 2011, 43, 166-180. 
72. Cornwell, B.; Laumann, E.O.; Schumm, L.P. The social connectedness of older adults: A national profile. Am. Sociol. Rev. 2008, 73, 185-203. [CrossRef] [PubMed]

73. Carstensen, L.L. The influence of a sense of time on human development. Science 2006, 312, $1913-1915$. [CrossRef] [PubMed]

74. Moen, P. The Gendered Life Course; George, L., Binstock, R.H., Eds.; Academic Press: San Diego, CA, USA, 2001.

75. Clarke, A.; Warren, L. Hopes, fears and expectations about the future: What do older people's stories tell us about active ageing? Ageing Soc. 2007, 27, 465-488. [CrossRef]

(c)

(C) 2017 by the authors. Licensee MDPI, Basel, Switzerland. This article is an open access article distributed under the terms and conditions of the Creative Commons Attribution (CC BY) license (http:/ / creativecommons.org/licenses/by/4.0/). 